\title{
O MITO DO HERÓI EM ZIGGY STARDUST
}

Saulo Atencio Pupo

\section{RESUMO}

Em 1972 David Bowie lançava o disco "The Rise And Fall of Ziggy Stardust and the Spiders From Mars" e se consagrava como um dos maiores nomes da música pop. Na concepção do álbum Bowie foi além da música e, captando o espírito de sua época, criou um álbum conceitual que se tornou referência para a música, moda e arte até os dias atuais. O disco conta a história de um alienígena andrógino que vem do espaço para anunciar a destruição da Terra; ao mesmo tempo, oferece a redenção por meio da celebração, ao modo dionisíaco. Ziggy desce à terra, se transforma e um rockstar e posteriormente se torna vítima de sua filosofia, atingindo a decadência e por fim, o suicídio, no melhor estilo sexo, drogas e rock'n'roll. Ziggy é o herói que não estava pronto para o fardo de sua própria missão e entra em colapso. O presente trabalho pretende analisar a mitologia presente na história de Ziggy Stardust a partir da abordagem de Joseph Campbell sobre o poder do mito, e o conceito de arquétipo presente na psicologia Jungiana.

Palavras chave: Ziggy Stardust. Mito. Herói.

\section{INTRODUÇÃO}

Como relata Doggett (2014), a sociedade nos anos 70 se encontrava aparentemente em um beco sem saída. Enquanto os anos 60 foram o ano da realização, do amor e do progresso, a década seguinte se mostrava mais sombria. Os ambientalistas anunciavam o esgotamento de recursos naturais fósseis para a produção de energia e as potências mundiais dividiam o mundo numa Guerra Fria, sob a constante ameaça de um confronto nuclear que poderia dizimar a civilização. A possibilidade de um conflito nuclear, o aumento do terrorismo no ocidente e a possibilidade de uma hecatombe climática, tornavam o fim do mundo uma possibilidade real. Segundo o autor, palavras como "declínio", “depressão" e "desespero" (DOGGETT, Peter 2014, p. 8) assombravam a sociedade dos anos 70 , que teve como principal característica a incapacidade de realizar os anseios da década anterior.

Bowie declarou em 1990:

Nos anos 70, as pessoas da minha idade não queriam pertencer a sociedade. Era como se pensássemos:'Tudo bem, a gente acabou com a unidade familiar, e a gente diz que está tentando sair de dentro da própria cabeça, que quer se expandir e tudo mais. Ótimo. Mas agora que a coisa aconteceu o que nos resta? Porque aqui estamos, sem as nossas famílias, totalmente fora de nossas cabeças, mas não fazemos a menor ideia de onde estamos'. Essa era a sensação no início dos anos 70 - ninguém sabia onde estava. (DOGGETT, Peter 2014, p. 22) 


\section{SEMINÁRIO DE PESQUISA EM CIÊNCIAS HUMANAS - SEPECH \\ Humanidades, Estado e desafios didático-científicos \\ Londrina, 27 a 29 de julho de 2016}

Nesse período, Bowie já não era um artista amador. Buscava o estrelato desde 1964 e passou por diversas bandas, estilos e abordagens da própria imagem. Como explica Doggett (2014, p. 9) "Desde o começo de sua carreira profissional, em 1964, Bowie recorrera à sua breve experiência junto à equipe de criação de uma agência de publicidade, para se reinventar, por meio de uma dúzia de personagens diferentes."

No documentário David Bowie and the Story of Ziggy Stardust (2012) Woody Woodmansey, baterista dos Spiders from Mars, afirma que Bowie estava buscando algo em comum entre o que ele poderia fazer e o que as pessoas desejavam, num período de tentativa e erro.

Ele estava em busca de uma fórmula, uma imagem ideal que o alavancaria para o estrelato como um ídolo definitivo ${ }^{1}$. Se inseria em diversos ambientes e gêneros musicais, absorvia o que lhe interessava e os abandonava.

\section{O DISCO: THE RISE AND FALL OF ZIGGY STARDUST AND THE SPIDERS FROM MARS}

No começo dos anos 70 Bowie já possuía uma arte profundamente madura, mesmo em relação a outros artistas consagrados como os Beatles ou os Rolling Stones. Em Space Oddity por exemplo, a celebrada corrida espacial é abordada de maneira melancólica, relatando uma missão falha que termina com o astronauta perdido no espaço.

Para Doggett (2014 p.9), essa "negatividade de Bowie parecia anacrônica, mas ela tãosomente antecipou a constatação de que a sociedade ocidental não poderia alimentar e satisfazer o otimismo da cultura jovem dos anos 60."

Lançado em 1972, The Rise and Fall of Ziggy Stardust and the Spiders From Mars é o quinto álbum de estúdio de David Bowie e é com ele que se solidifica como um ícone.

\subsection{Conceito do álbum}

Segundo Bowie descreve em entrevista à revista Rolling Stone (1974) a história do álbum começa em uma contagem regressiva para o fim do mundo. O planeta morrerá em cinco anos devido a escassez de recursos naturais. Os adultos enlouquecem com a notícia e acabam deixando os jovens à sua própria sorte. Então surge Ziggy Stardust, um alienígena que vem trazer uma palavra de salvação para os seres humanos. Ziggy é avisado em sonho por conselheiros sobre a chegada de um homem das estrelas (Starman), e deve anunciá-lo aos seres humanos. Assim ele o faz, e passa a encarar a si mesmo como um profeta do Starman que está no céu esperando para descer à terra. Depois torna-se um típico rockstar da época, usufruindo de drogas, groupies(inserir rodapé) e com o ego inflado.

Então os 'infinitos', seus conselheiros, chegam do espaço e pegam pedaços de Ziggy para que se tornem reais, pois anteriormente eles eram antimatéria e não poderiam

\footnotetext{
${ }^{1}$ Doggett (2014) explica que com o single Space Oddity, Bowie alcançara o 5 o lugar nas paradas britânicas o que o tornou relativamente famoso. Entretanto não emplacou nenhuma outra música e temia ser um artista de apenas um hit.
} 


\section{SEMINÁRIO DE PESQUISA EM CIÊNCIAS HUMANAS - SEPECH \\ Humanidades, Estado e desafios didático-científicos \\ Londrina, 27 a 29 de julho de 2016}

viver em nosso mundo. Eles o despedaçam enquanto está no palco, cantando Rock'n'Roll Suicide.

Porém, Bowie explica que a escassez de recursos causaria uma redução na espécie humana, mas não o fim do mundo. O fim de Ziggy ocorre quando é aniquilado por seus conselheiros ${ }^{2}$.

\section{MITO}

Ainda que não percebamos, os mitos nos cercam todo o tempo. Seja em contos infantis clássicos ou em filmes de super heróis, símbolos mitológicos povoam nossa imaginação.

Segundo Campbell (1991) os mitos servem para entrarmos em harmonia com o mundo, fazendo com que nossas ações reverberem no nosso ser e sintamos a experiência de estar vivos. Além disso, o mito trata de estágios da vida humana: infância, juventude, envelhecimento, emancipação, responsabilidades, etc. Nos ensinando lidar com determinados acontecimentos e etapas em nossas vidas.

Campbell (1997) também classifica o mito de acordo com sua função; aquele que relaciona o indivíduo com sua natureza e o mundo, e aquele que relaciona o indivíduo com a sociedade em que vive. Existe também a função que Campbell (1991, p. 807) denomina "pedagógica", que ensina "como viver uma vida humana sobre qualquer circunstância."

Finalmente, o autor define os mitos como sonhos arquetípicos, que lidam com os mais complexos problemas humanos, ensinando sobre decepção, encantamento, fracasso, sucesso e a busca de sentido para a experiência do indivíduo no mundo. Arquétipos são ideias elementares presentes no inconsciente coletivo presente em cada indivíduo. São "Formas ou imagens de natureza coletiva que se manifestam praticamente em todo o mundo como constituintes dos mitos e, ao mesmo tempo, como produtos autóctones e individuais de origem inconsciente." (JUNG, Carl C. apud CAMPBELL, Joseph 1997 p.26)

Para Campbell (1991) a única mitologia válida hoje seria a planetária. Uma mitologia que unisse os seres humanos como espécie, indo além de uma cultura regional.

E o único mito de que valerá a pena cogitar, no futuro imediato, é o que fala do planeta, não da cidade, não deste ou daquele povo, mas do planeta e de todas as pessoas que estão nele. [..] E ele lidará exatamente com aquilo que todos os mitos tem lidado - o amadurecimento do indivíduo, da dependência à idade adulta, depois à maturidade e depois à morte; e então com a questão de como se relacionar esta sociedade com o mundo da natureza e com o cosmos. (CAMPBELL, Joseph. 1991 p. 826)

\footnotetext{
${ }^{2}$ A narrativa não aparece no álbum explicitamente. A única referência aos 'assassinos' de Ziggy, por exemplo, está na letra da canção Ziggy Stardust que diz "when the kids have killed the man" ou seja, 'quando as crianças mataram o homem'. Em nenhum momento as palavras 'conselheiro' ou 'antimatéria' aparecem nas letras das músicas.
} 


\section{SEMINÁRIO DE PESQUISA EM CIÊNCIAS HUMANAS - SEPECH \\ Humanidades, Estado e desafios didático-científicos \\ Londrina, 27 a 29 de julho de 2016}

Devido a sua relevância ao presente trabalho, foram analisados alguns arquétipos específicos: o herói, a androginia, a queda e a morte.

\subsection{O herói}

Existem algumas etapas comuns na jornada do herói. Segundo Campbell (1991 p. 319) o herói é um "homem ou mulher que conseguiu vencer suas limitações históricas pessoais e locais e alcançou formas normalmente válidas, humanas" e também aquele que dá sua vida em troca dessa realização.

Assim, saindo da vida cotidiana, se aventura em um mundo distante, povoado pelo sobrenatural e desconhecido, obtém a vitória e retorna com o poder ou conhecimento para trazer benefícios aos seus semelhantes e trazendo meios para a regeneração da sociedade.

Campbell (1991) faz uma diferenciação entre contos populares, que normalmente relacionam a jornada heróica com uma proeza física, com o ponto de vista moral, das religiões mais elevadas. Na proeza física o herói realiza um ato de coragem em uma batalha ou salva uma vida por exemplo. Na proeza moral, o herói "aprende a lidar com o nível superior da vida espiritual humana e retorna com uma mensagem." (CAPMBELL, Joseph. 1991, pos 2469)

\subsection{Androginia e queda}

O mito da androginia é antigo e está presente em diversas culturas. De acordo com Eliade (s.d) nas literaturas inglesas e francesas decadentes o andrógino era abordado como um hermafroditismo mórbido, que apenas proveria maiores possibilidades eróticas. O autor afirma que esta é uma degradação do símbolo, que incompreendido, passa a ser representado de maneiras grosseiras e decadentes.

Já para os românticos alemães, "o andrógino era o tipo de homem perfeito do futuro"(ELIADE s.d p. 38). Franz von Baader (apud Eliade s.d) acreditava que o andrógino era uma criatura primordial: estava presente no começo dos tempos e também estaria no fim. Em diversas culturas, a bissexualidade estava presente em deuses que se auto fecundavam, sendo uma representação da força criadora e da vida. $\mathrm{Na}$ visão cristã da criação do mundo Adão foi criado com ambos os sexos: "Quando o Santíssimo, Bendito seja Ele, criou o primeiro homem, fê-lo andrógino ${ }^{3}$." Segundo Campbell (1991) o momento da criação de Eva, a remoção da parte feminina de Adão, simboliza o início da queda. A partir da divisão, o homem passou de um ser perfeito para um ser dual imperfeito, e em seguida descobriu a dualidade entre bem e mal, fazendo com que fosse expulso do paraíso.

Campbell (1991) explica que após a queda do Éden, passamos a ver a natureza e o mundo por consequência, como corrompidos. No pensamento cristão, qualquer ato espontâneo e natural passa a ser visto como pecaminoso e deve ser reprimido, como exemplo o sexo. Já para Baader (apud Eliade s.d) o sexo entre homem e mulher teria a

\footnotetext{
${ }^{3}$ Midrash, comentário sobre o Gênesis, Rabbah 8:1. apud Campbell, 1997.
} 


\section{SEMINÁRIO DE PESQUISA EM CIÊNCIAS HUMANAS - SEPECH \\ Humanidades, Estado e desafios didático-científicos \\ Londrina, 27 a 29 de julho de 2016}

função de integrá-los novamente ao ser humano completo, e reconectá-lo a sua divindade original.

\subsection{Morte e sacrifício}

Campbell (1991) afirma que apesar da conotação comumente negativa, a morte traz um significado de transformação, pois para que uma nova geração possa surgir, a anterior precisa ser destruída.

No caso do herói, a morte é seu último ato. Entretanto ela não lhe causa medo, pois a "primeira condição do heroísmo é a reconciliação com o túmulo" (CAMPBELL, Joseph. 1997, p180) Dar a vida por algo maior que si mesmo é característica fundamental do herói. Assim, o suicídio é considerado também um ato simbólico, pois aquele que o faz rejeita o estado psicológico atual, buscando ingressar em uma nova forma de vida.

Cambpell (1991) explica que existe uma diferença entre nascer no mundo e participar voluntariamente do ciclo de vida nele, como na mitologia cristã, em que Jesus abre mão de sua condição divina para ser crucificado na terra, redimindo a humanidade de seus pecados.

Da vida sacrificada nasce uma nova, que pode ser ou não a vida do herói, mas uma nova forma de ser e agir.

\section{ANÁLISE}

Foram selecionadas cinco músicas do álbum para serem analisadas mais cuidadosamente devido a sua relevância e riqueza simbólica: Moonage Daydream, Starman, Lady Stardust, Ziggy Stardust e Rock'n'Roll Suicide.

Em Five Years, primeira faixa do disco, é anunciado o fim do mundo. Restam apenas cinco anos para a Terra, e o motivo de seum fim não é explicado. A faixa seguinte, Soul Love é "uma canção sobre criatividade sufocada e cinismo" que "destruía todas as ilusões - religião, política, romance e idealismo” (DOGGETT 2014, p. 187).

\subsection{Moonage Daydream}

O título Devaneio da Era Lunar, em sua tradução literal, pode se referir às missões Apollo e a chegada do homem na lua, ou aos antigos cultos de adoração a esta, em que a "deusa da Lua era a deusa da magia, do subconsciente, da inspiração poética". (COLIN, Wilson apud DOGGETT, Peter, p. 137). Campbell (1991) levanta a hipótese de a Lua ser a mitologia universal do futuro, pois nela não vemos as divisões em países como na Terra.

A terceira música do disco é narrada porZiggy Stardust, que logo nos primeiros versos demonstra sua personalidade predatória, andrógina, e dominante, bem como suas ambições de tornar-se uma estrela.

Apesar da origem superior, Ziggy parece ter uma profunda inclinação às paixões humanas, como demonstra o verso "the church of man love/ is such a holy place to 


\section{SEMINÁRIO DE PESQUISA EM CIÊNCIAS HUMANAS - SEPECH \\ Humanidades, Estado e desafios didático-científicos \\ Londrina, 27 a 29 de julho de 2016}

be"4 . Com essa afirmação ele nega os valores espirituais ao demonstrar apreço à citada igreja do homem e demonstra uma androginia erótica, mais próxima ao que Eliade (s.d) relaciona com seu conceito decadente. Não há na letra nenhum indicativo de uma sabedoria superior ou elevado desenvolvimento espiritual.

Ao cair na terra mantendo sua bissexualidade, Ziggy se apresenta como uma espécie de Deus (pois vem do céu) que caminha entre os homens, mas participa de suas paixões.

\subsection{Starman}

O rádio tocava rock'n'roll quando a estação fica fora do ar. Surge Ziggy em uma transmissão cósmica, anunciando a vinda do homem das estrelas. Um jovem que ouvia o rádio liga para um amigo e sugere que ambos liguem a TV, onde Ziggy talvez apareça. Ao surgir no rádio e na TV para anunciar a vinda de Starman, Ziggy se apresenta à humanidade como um messias artista. Doggett (2014) afirma que a música pode tratar de uma metáfora à estrela de rock, que na época era encarada como um messias, um salvador, ou um líder.

A mensagem do 'homem das estrelas' é moralmente elevada, beirando a incompreensão, como é sugerido nos trechos "esperando no céu" que se refere a um ser em um plano superior, transcendental; e "ele gostaria de nos conhecer, mas teme explodir nossas mentes". Ziggy se coloca como seu profeta, pois está na terra falando com os homens ao mesmo tempo que traz a mensagem seres superiores. Se enquadra aqui a ideia de herói realizador de uma proeza moral descrita por Campbell (1991), porém a imagem do profeta sexual, predatório, mundano contrasta com a imagem do ser divino que anuncia .

\subsection{Lady Stardust}

A sexta música do álbum traz a personagem no auge de sua androginia. Apesar do vocábulo Lady se referir ao feminino, o interlocutor se refere à Ziggy apenas com pronomes masculinos. Lady Stardust sobe no palco e mesmo que as pessoas estivessem rindo de seu longo cabelo, maquiagem e uma graça animal, e cantasse músicas de 'escuridão e desânimo' Ziggy ou Lady Stardust parecia estar em plenitude. A música afirma que "ele estava bem", pois a "banda estava reunida e o som duraria para sempre". Se encontrava em um estado de profunda realização.

A plenitude, justo no momento mais andrógino do personagem, o aproxima da ideia da androginia como característica divina, em equilíbrio com seus lados masculino e feminino. Como explica Doggett (2014) a melodia possui clara influencia de Elton John $^{6}$. O vocal suave e melancólico de Bowie reforça o momento de paz encontrado por Lady Stardust.

\footnotetext{
${ }^{4}$ Disponível em <http://www.davidbowie.com/>

${ }^{5}$ Do original "And he was alright, the band was altogether/Yes he was alright, the song went on forever" disponível em www.davidbowie.com
} 


\section{SEMINÁRIO DE PESQUISA EM CIÊNCIAS HUMANAS - SEPECH \\ Humanidades, Estado e desafios didático-científicos \\ Londrina, 27 a 29 de julho de 2016}

Entretanto o equilíbrio de Ziggy começa a declinar nas faixas seguintes: em Star o artista se perde nos devaneios sobre ser uma estrela de rock, enquanto em Hang on to Yourself narra suas aventuras sexuais com jovens fãs.

\subsection{Ziggy Stardust}

Uma das faixas mais significativas do álbum, Ziggy Stardust é narrada pela banda Spiders From Mars, e mostra o auge do sucesso de Ziggy e sua queda. Segundo Doggett (2014) por meio de elementos simbólicos, a letra destaca a importância das características típicas de um rockstar que era o herói típico da época. Ziggy é habilidoso, especial, adorado, inconsequente e sexualmente bem dotado. Seu aspecto messiânico é relatado com ironia: "He was the nazz / with Godgiven ass". Sua personalidade, de acordo com o autor, encaminharia o personagem para o clímax inevitável: ego inflado, alienação (afinal, quem se relacionaria com um messias leproso) e por fim, a desintegração.

Diferentemente da versão narrada à Rolling Stone por Bowie, aqui tem-se ai impressão que são os fãs que matam o astro no palco, e não conselheiros invisíveis ${ }^{8}$. Como afirma o músico Gary Kemp no documentário David Bowie and the Story of Ziggy Stardust (2012), "Esse super astro é assassinado por seus próprios fãs... Era uma ideia que adaptou da distopia da época." A distopia a que Kemp se refere é o caos em que se encontrava o mundo e especialmente a Inglaterra nos anos 70. Como ele complementa em seguida:

Em 1972 ainda haviam vestígios de bombardeios. E havia recessão. Era a época da guerra fria e acredito que o que David e Ziggy ofereciam era uma criatura fantasiosa para nos salvar. Ele cantava "só restam cinco anos de vida para a terra". E de fato em 1972, você acreditava de fato que só restavam cinco anos.

Ainda que sua intenção fosse o autossacrifício, a frase "he took it all too far" os excessos de seu estilo de vida também causaram sua queda. "Making love with his ego/ Ziggy sucked up into his mind/ Like a leper messiah", Suas características mundanas, e seu padecimento humano e não divino criam uma relação de proximidade com as pessoas. Como explica Campbell (1991) é Cristo sofrendo na cruz como homem que desperta a compaixão.

Como afirma Doggett (2014), a letra de Ziggy Stardust descreve toda a jornada do alienígena diferentemente da jornada comum do herói descrita por Campbell (1991) que vai para uma aventura mítica e retorna com uma mensagem, Ziggy vem do espaço, um lugar mítico, e sua aventura começa quando desce à Terra e passa a viver como um homem.

\footnotetext{
${ }^{6}$ Como afirma Doggett, a referência não é acidental, tendo em vista que Elton John também era um ícone bisexual da música.

${ }^{7}$ Nazz poderia se referir "ao grande contador de histórias Lorde Buckley, e suas histórias sobre Jesus de "Naz". (DOGGETT, Peter. 2014 p. 141). disponível em <www.davidbowie.com>

${ }^{8}$ Doggett, também considera que Bowie foi morto pelos fãs: "Ziggy se deixava assassinar pelos fãs; portanto ele era, de certo modo, um suicida."

${ }^{9}$ disponível em <www.davidbowie.com>
} 


\section{SEMINÁRIO DE PESQUISA EM CIÊNCIAS HUMANAS - SEPECH \\ Humanidades, Estado e desafios didático-científicos \\ Londrina, 27 a 29 de julho de 2016}

\subsection{Rock'n'Roll Suicide}

A última faixa do álbum encerra a saga de Ziggy Stardust, que culmina em sua morte. A canção traz o que talvez seja a mensagem mais importante da obra: "you're not alone" ${ }^{\text {"10 }}$. Encerrando seus shows com esta mesma canção, Bowie cantava e permitia que seus fãs tocassem a ponta de seus dedos. Doggett (2014) explica que ele agia como uma figura paterna, um tio ou irmão que compreendia a falta de autoconfiança que os jovens sofriam. Portanto, "o consolo de Bowie era demonstrar consciência de que seus fãs padeciam das angústias da adolescência" (DOGGETT, Peter. 2014 p. 197).

Na narrativa do álbum ele sacrifica seu personagem que morre pelos seus fãs para que eles encontrem redenção, pois como demonstra Campbell (1991) o herói se sacrifica para que outra vida surja, ainda que não seja a dele. A morte de Ziggy serviu para que seus fãs seguissem em frente.

\section{CONCLUSÃO}

Para criar um personagem arrebatador, Bowie utilizou magistralmente o imaginário coletivo de sua época. $\mathrm{O}$ apocalipse, que era antes narrativa pertencente às religiões, tornou-se também uma preocupação secular com a guerra fria e o aquecimento global, e serviu como pano de fundo para abordar os anseios de uma sociedade pessimista.

Ao conquistar a liberdade pela qual lutaram nos anos 60, os jovens abandonaram a sociedade, a família e seus valores, como relatou Bowie. Esse abandono de vínculos criou um vácuo de modelos a serem seguidos, que foi possivelmente ocupado pelas celebridades.

Para Cambpell (1991, p. 2986) "O grande problema na vida de qualquer jovem é encontrar modelos que sugiram possibilidades. [...] Um mito vivo pode oferecer nos modelos atuais."

Bowie criou um personagem com um amplo potencial de identificação pelo público, como demonstra Doggett (2014 p.9) Ziggy "seria masculino e feminino, gay e hétero, humano e alienígena, um eterno estranho, capaz de servir de ponto de referência para qualquer indivíduo que se sentisse à margem do mundo que o cercava." O mito de Ziggy se encaixava perfeitamente às necessidades de uma juventude carente em um mundo caótico.

Apesar justamente despertar o desejo dos jovens, o mito de Ziggy desmistifica a aura profética atribuída aos rockstars da época, expondo seu lado decadente e mundano. $\mathrm{O}$ herói de Bowie parece zombar de si mesmo, pois é como ele mesmo define, um messias leproso que deseja salvar o mundo mas não consegue salvar a si próprio.

A maior evidência disso é que, diferente de outros artistas que como Ziggy levaram "tudo longe demais" como Jimmy Hendrix, Janis Joplin, Brian Jones e Jim Morrison, Bowie seguiu em frente com sua vida e carreira, conseguindo inclusive abandonar vício em drogas que levou os citados rockstars à morte.

Em 1973, Bowie anuncia no palco antes da última música, para surpresa até mesmo de seus companheiros de banda "este é nosso último show". Ziggy foi sacrificado por

10 disponível em <www.davidbowie.com> 


\section{SEMINÁRIO DE PESQUISA EM CIÊNCIAS HUMANAS - SEPECH \\ Humanidades, Estado e desafios didático-científicos \\ Londrina, 27 a 29 de julho de 2016}

seus fãs na narrativa do álbum e depois sacrificado novamente por Bowie, como se estivesse trazendo efetivamente a mensagem do alienígena para o mundo real. Ziggy Stardust e sua mitologia já eram coisa do passado e Bowie, assim como a sociedade, precisava se reinventar.

\section{REFERÊNCIAS}

BOWIE, David. Beat Godfather Meets Glitter Mainman. Londres: 1973. Rolling Stone, edição digital. Entrevista concedida a William Seward Burroughs. disponível em: http://www.rollingstone.com/music/news/beat-godfather-meets-glitter-mainman19740228

CAMPBELL, Joseph. O poder do mito. Editora Palas Atena, 1991. Edição Kindle

CAMPBELL, Joseph. O herói de mil faces. ed. 10. Editora Pensamentos LTDA, 1997. PDF.

ELIADE, Mircea. Mefistofeles y el andrógino. [S.l.: s.n., s.d.] edição digital. Disponível em: <http://www.laescalerasophia.com.ar/biblioteca/Eliade mefistofeles androgino.pdf> acesso em 13 mai 2016.

DAVID Bowie and the Story of Ziggy Stardust. Direção de James Hale. 2012. 60 min. disponível em $<$ https://www.youtube.com/watch?v=D3DvaQNv5QI $>$ acesso em 8 mai 2016.

David Bowie - Site Oficial. disponível em: <http://www.davidbowie.com/> acesso em 25 mai 2016.

DOGGETT, Peter. O homem que vendeu o mundo. Ed. Nossa Cultura, 2014. 